\title{
GARTER SNAKE EATS LEECH
}

PHILIP S. TAYLOR Saskatoon, SK tel (306) 665-6371

11 June, 2014 in the Thickwood Hills, North of Redberry Lake. A young Red-sided Garter Snake (Thamnophis sirtalis) was capturing and eating a leech (species unknown). The snake was just over $30 \mathrm{~cm}$ in length; the leech about $8 \mathrm{~cm}$. Garter snakes are known to prey on leeches as they share habitats including the shallow water at pond and marsh edges.

"Although garter snakes are not considered venomous, they have a gland above the upper jaw on either side (corresponding to the venom gland of vipers and other venomous snakes) that produces potentially toxic secretions. In general, bites from garter snakes are harmless because these snakes lack fangs and thus cannot efficiently inject the gland's secretions. However, prolonged bites by western terrestrial and common garter snakes have caused swelling and localized bleeding in people, presumably because unusually large amounts of the secretions seeped into the victims. The "venom" of garter snakes may help them overcome prey, but this has not yet been studied."

http://www.onlinenevada.org/ articles/garter-snakes

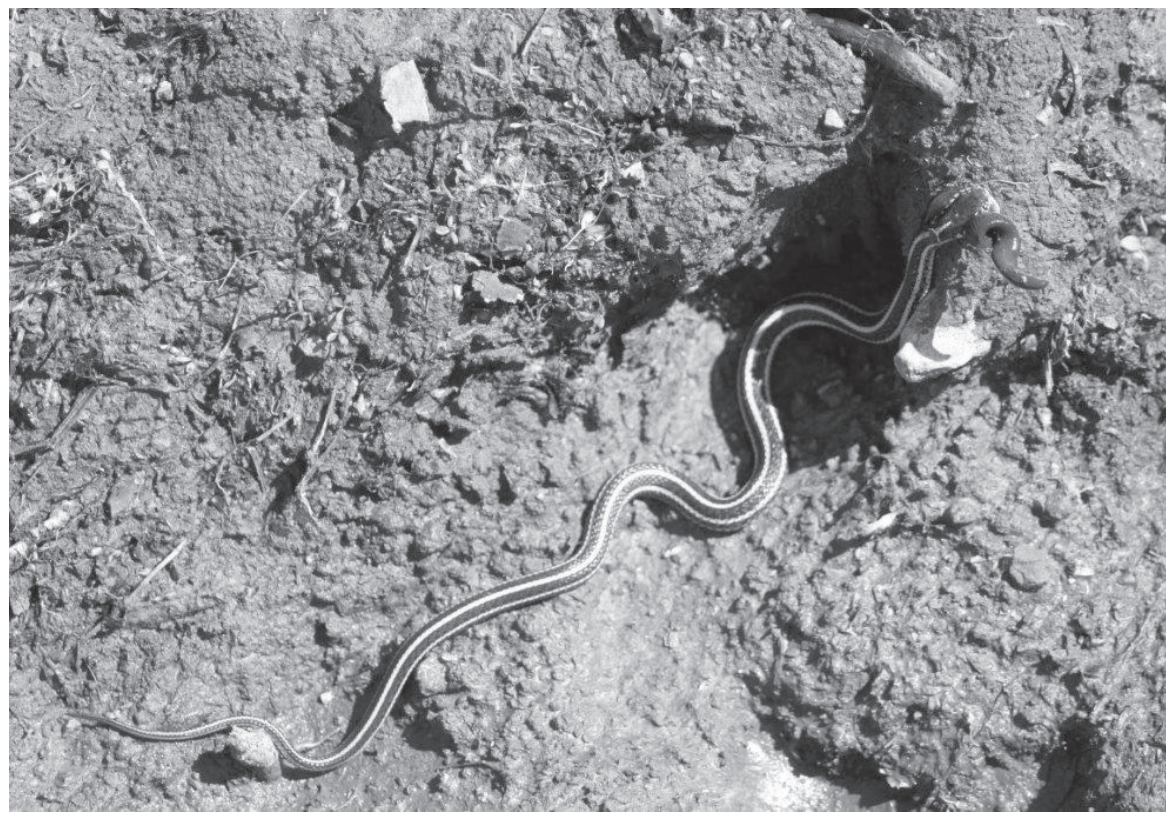

- Philip S. Taylor 


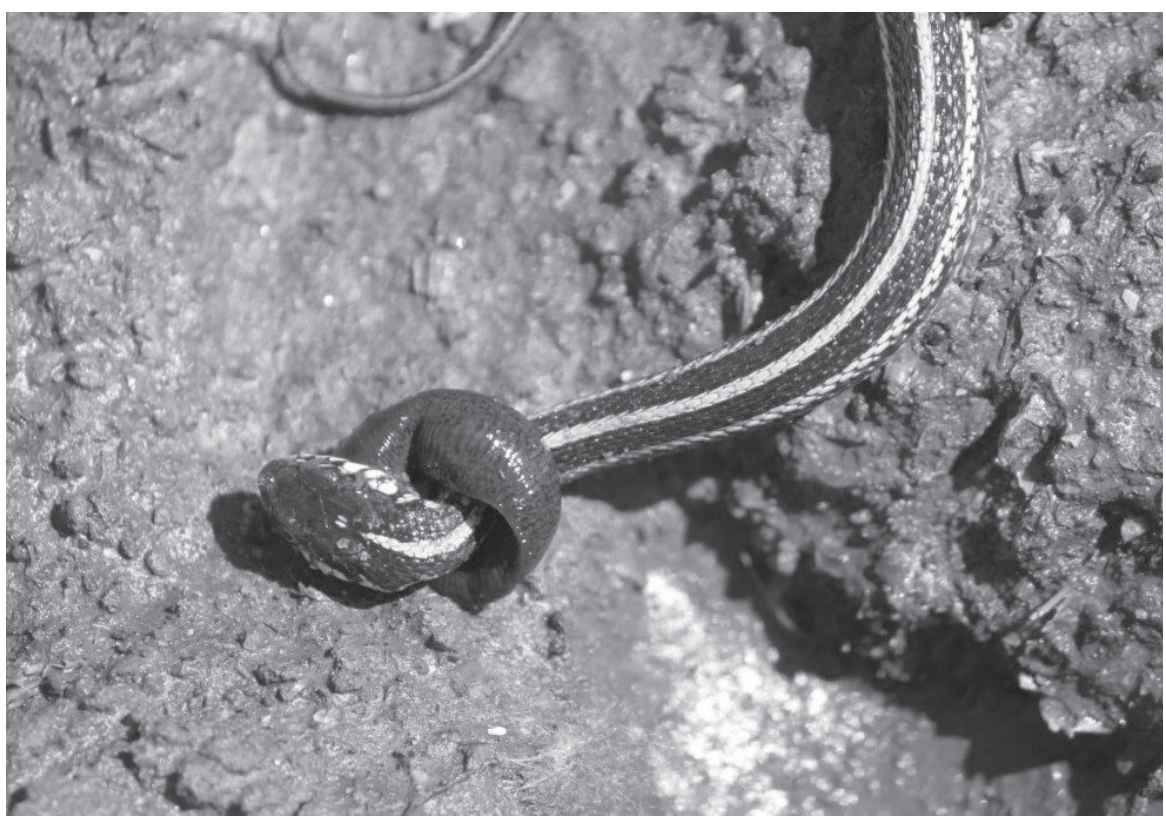

- Philip S. Taylor

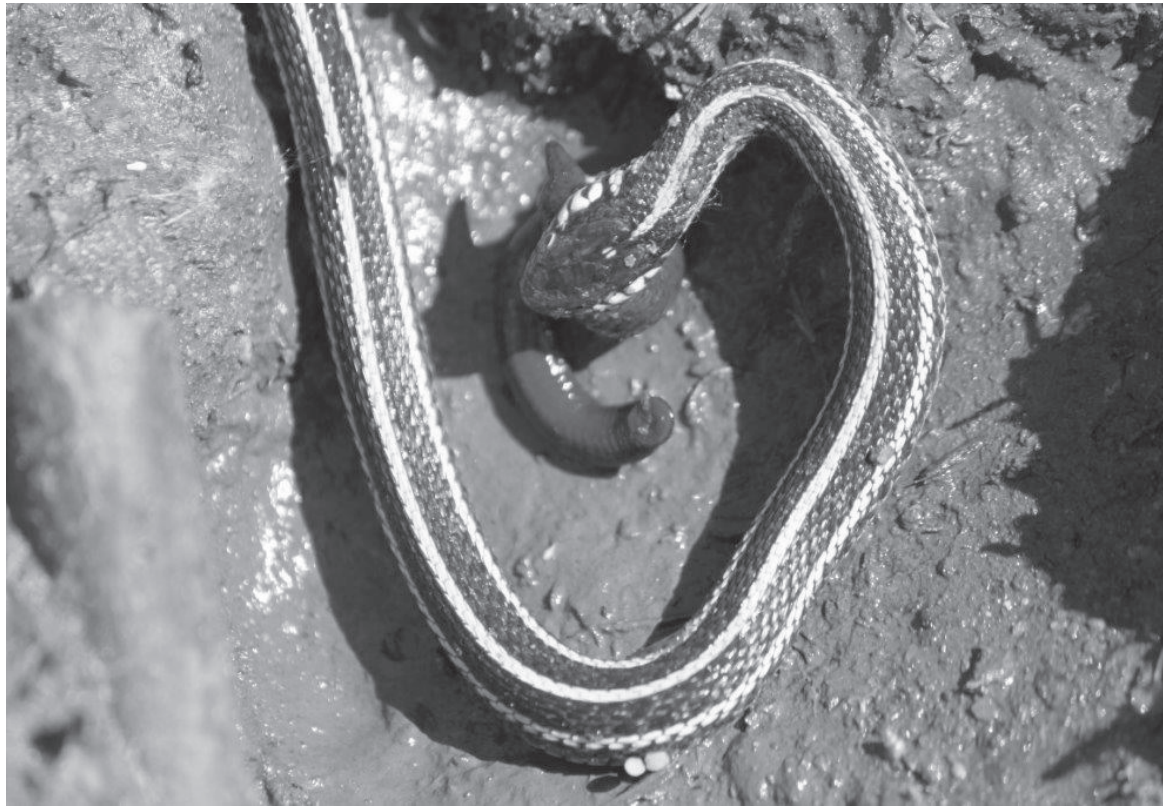

- Philip S. Taylor 